\title{
Separation of Different Ion Structures in Atmospheric Pressure Photoionization-Ion Mobility Spectrometry-Mass Spectrometry (APPI-IMS-MS)
}

\author{
Jaakko Laakia, ${ }^{a}$ Alexey Adamov, ${ }^{\text {a,b }}$ Matti Jussila, ${ }^{a}$ Christian S. Pedersen, \\ Alexey A. Sysoev, ${ }^{\text {d,e }}$ and Tapio Kotiaho ${ }^{\mathrm{a}, \mathrm{b}}$ \\ ${ }^{a}$ Laboratory of Analytical Chemistry, Department of Chemistry, University of Helsinki, Helsinki, Finland \\ ${ }^{b}$ Division of Pharmaceutical Chemistry, Faculty of Pharmacy, University of Helsinki, Helsinki, Finland \\ ${ }^{\mathrm{c}}$ Department of Chemistry, University of Copenhagen, Copenhagen, Denmark \\ d National Research Nuclear University MEPhI, Moscow, Russia \\ e Linantec Ltd., Moscow, Russia
}

This study demonstrates how positive ion atmospheric pressure photoionization-ion mobility spectrometry-mass spectrometry (APPI-IMS-MS) can be used to produce different ionic forms of an analyte and how these can be separated. When hexane:toluene (9:1) is used as a solvent, 2,6-di-tert-butylpyridine (2,6-DtBPyr) and 2,6-di-tert-4-methylpyridine (2,6-DtB-4-MPyr) efficiently produce radical cations $[\mathrm{M}]^{+\cdot}$ and protonated $[\mathrm{M}+\mathrm{H}]^{+}$molecules, whereas, when the sample solvent is hexane, protonated molecules are mainly formed. Interestingly, radical cations drift slower in the drift tube than the protonated molecules. It was observed that an oxygen adduct ion, $\left[\mathrm{M}+\mathrm{O}_{2}\right]^{+*}$, which was clearly seen in the mass spectra for hexane:toluene $(9: 1)$ solutions, shares the same mobility with radical cations, $[\mathrm{M}]^{+\cdot}$. Therefore, the observed mobility order is most likely explained by oxygen adduct formation, i.e., the radical cation forming a heavier adduct. For pyridine and 2-tert-butylpyridine, only protonated molecules could be efficiently formed in the conditions used. For 1- and 2-naphthol it was observed that in hexane the protonated molecule typically had a higher intensity than the radical cation, whereas in hexane:toluene $(9: 1)$ the radical cation $[\mathrm{M}]^{+\cdot}$ typically had a higher intensity than the protonated molecule $\left[\mathrm{M}+\mathrm{H}^{+}\right.$. Interestingly, the latter drifts slower than the radical cation $[\mathrm{M}]^{+}$, which is the opposite of the drift pattern seen for 2,6-DtBPyr and 2,6-DtB-4-MPyr. (J Am Soc Mass Spectrom 2010, 21, 1565-1572) @ 2010 American Society for Mass Spectrometry

$\mathrm{I}$ $\mathrm{n}$ ion mobility spectrometry (IMS) ions move through an applied electric field in a drift gas flow [1]. Interactions between analyte ions and the drift gas result in a specific drift time for that ion, which is often converted to the reduced mobility (Formula 1) [1, 2]. Several general reviews of IMS exist $[1,3-8]$ and the theory behind drift tube ion mobility spectrometry has been presented in detail elsewhere $[2,9]$.

$$
K_{0}=\left(\frac{l_{d}^{2}}{t_{d} V}\right)\left(\frac{273}{T}\right)\left(\frac{P}{760}\right)
$$

where $l_{d}=$ length of the drift region, $t_{d}=$ drift time of ion, $\mathrm{V}=$ voltage drop over the drift region, $\mathrm{T}=$ temperature, and $\mathrm{P}=$ pressure.

Address reprint requests to Mr. J. Laakia, Department of Chemistry, P.O. Box 55, FI-00014 University of Helsinki, Finland. E-mail: jaakko.laakia@ helsinki.fi or Prof. Tapio Kotiaho, Faculty of Pharmacy, Division of Pharmaceutical Chemistry, P.O. Box 56 (Viikinkaari 5E), 00014 University of Helsinki, Finland and Laboratory of Analytical Chemistry, Department of Chemistry, A.I. Virtasen aukio 1 (P.O. Box 55), 00014 University of Helsinki, Finland. E-mail: tapio.kotiaho@helsinki.fi
The most common IMS devices are stand-alone instruments, which are commonly used to screen the environment for significant chemicals such as warfare agents, explosives, and illegal drugs [1, 10-12]. These devices are often tuned to detect certain chemicals; when more specific information is required, IMS is often combined with other instruments, for example with gas chromatography (GC-IMS) [4, 13]. Ion mobility spectrometry-mass spectrometry (IMS-MS) is also becoming more and more popular in various application fields, especially in bioanalysis [5]. Several different types of ion mobility spectrometers have been combined with mass spectrometers, e.g., drift tube IMS-MS [1, 5, 14], field asymmetric ion mobility spectrometry (FAIMS-MS) [5, 15-17], and also an aspiration IMS method has been combined with MS [18]. In bioanalysis, a common application of IMS-MS is structural studies of peptides and proteins [19-22]. Lately, it has also been shown that drift tube IMS-MS can be used, for example, to separate carbohydrate isomers [23] and enantiomers of model compounds [24, 25].

Ionization in ion mobility spectrometry is usually conducted with radioactive ionization (e.g., ${ }^{63} \mathrm{Ni}$ ), how- 
ever ionization techniques such as electrospray ionization (ESI) and atmospheric pressure chemical ionization (APCI) have also often been used [1, 5, 22, 26-29]. Atmospheric pressure photoionization (APPI) is an ionization technique that has shown its strength, especially in LC-MS during the past decade [30, 31]. However, APPI has already been used with IMS in 1980s [13]. An important advantage of APPI compared to ESI is that APPI is capable of ionizing less polar compounds $[30,32]$. Together with drift tube ion mobility spectrometry, APPI has been used for example to detect alcohols [33] and toluene [34]. Borsdorf et al. have compared APPI with APCI and ${ }^{63} \mathrm{Ni}$ in the analysis of various aromatic compounds and terpenes and observed some variance in the mobility spectra depending on the ionization method [35-38]. Still, the number of publications with APPI-IMS is limited. In our group APPI-IMS has been used, for example, to measure mobility of 2,6-di-tert-butylpyridine (2,6-DtBPyr), which has been proposed for use as a mobility standard [39]. Interestingly, in some of these measurements, two different mobility peaks were observed using our high-resolution drift tubes. Preliminary mass-selected mobility measurements showed that one of the peaks was due to the $[\mathrm{M}]^{+\cdot}$ ion of 2,6-DtBPyr and the other one due to the $[\mathrm{M}+\mathrm{H}]^{+}$ion [40]. To further study this observation and possibility separate radical cations and protonated molecules of the same compound by IMS, a set of analytes was selected (Figure 1); the fact that depending on the ionization conditions radical cations or protonated molecules can be produced in APPI guided the selection [41-43]. The results of these studies and the reasons for the observed differences in mobilities of different ions of the model compounds are presented.

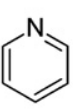

Pyridine $\left(M_{r}=79.10\right)$

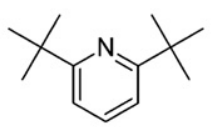

2,6-Di-tert-butylpyridine (2,6-D $t$ BPyr, $\left.M_{r}=191.31\right)$

2,6-Di-tert-butyl-4-methylpyridine (2,6-D $t$ B-4-MPyr, $\left.M_{r}=205.34\right)$
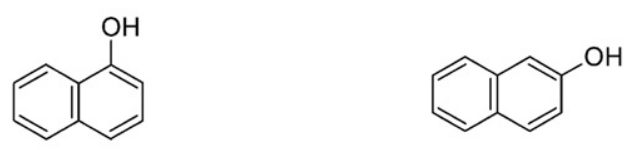

1-Naphthol $\left(M_{r}=144.17\right)$

2-Naphthol $\left(M_{r}=144.17\right)$

Figure 1. The structures of the compounds investigated in this study.

\section{Experimental}

\section{Instrumentation}

Two different drift tube IMS instruments were used in this study. Most of the measurements were done with the IMS-MS instrument described in more detailed previously [14]. In addition, some measurements were done with an ion mobility spectrometer-faraday plate detector (IMS-FP) instrument [44]. Briefly, in the IMS-MS instrument, the dual Bradbury-Nielsen (B-N) [45] gate cylinder drift tube is attached to a commercial triplequadrupole mass spectrometer API-300 (SCIEX Applied Biosystems, Toronto, ON, Canada). These two B-N gates allow the selection of a mobility window [14, 46]. The gate opening time for both B-N gates was $300 \mu$ s. Nitrogen was used as the drift gas with a flow of $\sim 2.4$ $\mathrm{L} / \mathrm{min}$. The length of the drift region is $13.3 \mathrm{~cm}$ and voltage drop was set from 4.20 to $4.83 \mathrm{kV}$ (from 316 to $363 \mathrm{~V} / \mathrm{cm}$ ), unless stated otherwise. Mass spectrometric parameters were typically a declustering potential from 20 to $30 \mathrm{~V}$, unless otherwise stated, a focusing potential of 130 to $220 \mathrm{~V}$, and an entrance potential of 5 to $10 \mathrm{~V}$. Full scan mass spectra were usually collected in the range of $m / z \quad 30-300$ in 1-s scan time, and sometimes with a range of $m / z 50-500$. Product ion mass spectra were measured in a mass range of $m / z 30$ to 200 or 300 , and the collision energy varied from 15 to $40 \mathrm{~V}$. Massselected ion mobility data were measured using the selected ion monitoring (SIM) mode of the instrument and the typical mobility spectrum measurement time was $\sim 10-15 \mathrm{~min}$. The software used for data collection was Analyst 1.4.1 (Applied Biosystems/MDS SCIEX, Concord, ON, Canada). In the IMS-FP instrument, the total drift length is $13.85 \mathrm{~cm}$ and it was operated with one B-N gate with a gate opening time of $100 \mu \mathrm{s}$. The drift voltage was $5.24 \mathrm{kV}$, which equals $378 \mathrm{~V} / \mathrm{cm}$, and the nitrogen drift gas flow was set to $2.1 \mathrm{~L} / \mathrm{min}$. Data were collected by utilizing a custom-made program in a LabVIEW environment (National Instruments, Austin, TX, USA). Also, some data were transferred to a ChemStation rev. 10.02 (Agilent Technologies, Inc., Palo Alto, CA, USA) and further processed with custom-made macros. In this study, 2000 measurements were combined for the mobility spectra. A nitrogen delivery system, which produces $99.5 \%$ pure nitrogen gas from compressed air for drift and nebulizer gas, was described previously [14, 47, 48]. Experiments were conducted at room temperature and atmospheric pressure. Temperature was measured with a thermometer (Thermatag; Digitron Instrumentation Ltd., Torquay, England) which was attached to the nitrogen storage tank, and the pressure meter (Series 902; MKS Instrument, Andover, MA, USA) was located within the laboratory.

In both instruments, atmospheric pressure photoionization was carried out using a custom-made ion source in which a krypton discharge lamp is used (model PKS 100; Heraeus Noblelight, Cambridge, UK). It produces two energy packets, with $10 \mathrm{eV}$ (main packet) and $10.6 \mathrm{eV}$, 
which equal in wave lengths of 124 and $117 \mathrm{~nm}$, respectively. Sample feeding to the ion source was carried out with a custom-made heated nebulizer, which was heated up to $573 \mathrm{~K}$. Samples were injected into the nebulizer with a PHD 2000 Advanced Syringe Pump (Harvard Apparatus GmbH, Hugstetten, Germany). The nebulizer nitrogen gas flow was typically set at 1.6 to $1.8 \mathrm{~L} / \mathrm{min}$. In some measurements, a custom-made gas calibrator was used for sample introduction. In this system, analyte solutions are directly injected, without heating, into the nitrogen sample gas stream $(1.9 \mathrm{~L} / \mathrm{min})$ using the syringe pump.

\section{Chemicals}

Chemicals used in the study were: $n$-hexane with a purity of $>95 \%$ (POCH, SA, Gliwice, Poland), HPLCgrade toluene (Lab-Scan, Dublin, Ireland), n-pentane with a purity of $>99 \%$ (Fluka, Steinheim, Germany), HPLC-gradient-grade methanol (J. T. Baker, Denventer, Holland), pyridine with a purity of $>99.5 \%$ (Merck, Darmstadt, Germany), 1-naphthol, 2-naphthol, 2-tertbutylpyridine (2-tBPyr), 2,6-di-tert-butylpyridine (2,6DtBPyr) with a purity of $>97 \%$ and 2,6-di-tert-butyl-4methylpyridine (2,6-DtB-4-MPyr from Sigma-Aldrich, Steinheim, Germany) with a purity of $>98 \%$. All the chemicals were purchased and used as received. Solutions of 2,6-di-tert-butylpyridine, at two different concentrations, were made in the solvent to give 50 or 500 $\mu \mathrm{M}$ (IMS-FP measurements), which equals a gas-phase concentration of 2 or $20 \mathrm{ppb}$, respectively. Other compounds typically had solution concentrations of 50 or $100 \mu \mathrm{M}$, which equal gas-phase concentrations of about 1 to $10 \mathrm{ppb}$, depending on the compound concerned. Most of the solutions were prepared in hexane, or hexane:toluene (9:1). Only a few solutions were made in methanol:toluene (9:1), or pentane:toluene (9:1).

\section{Results and Discussion}

\section{Atmospheric Pressure Photoionization (APPI)}

One of the main points of the study was to select the APPI ionization conditions so that a radical cation and/or protonated molecule could be efficiently formed for the model compounds (Figure 1). All the pyridine compounds produced a protonated molecule $[\mathrm{M}+\mathrm{H}]^{+}$in APPI when they were dissolved in hexane. Low level production of the $[\mathrm{M}]^{+\cdot}$ ion was also observed for 2,6-DtBPyr and 2,6-DtB-4-MPyr in hexane (Figure 2a). However, when the sample solvent was hexane:toluene (9:1), radical cations were clearly observed for 2,6D tBPyr and 2,6-DtB-4-MPyr (Figure 2b). In these conditions, pyridine and 2-tBPyr formed efficiently only the protonated molecule. A radical cation $[\mathrm{M}]^{+\cdot}$ of toluene at $\mathrm{m} / \mathrm{z} 92$ was typically observed in the APPI mass spectra measured for samples in hexane:toluene $(9: 1)$. This is in good agreement with the results reported earlier [41]. The fact that the toluene radical

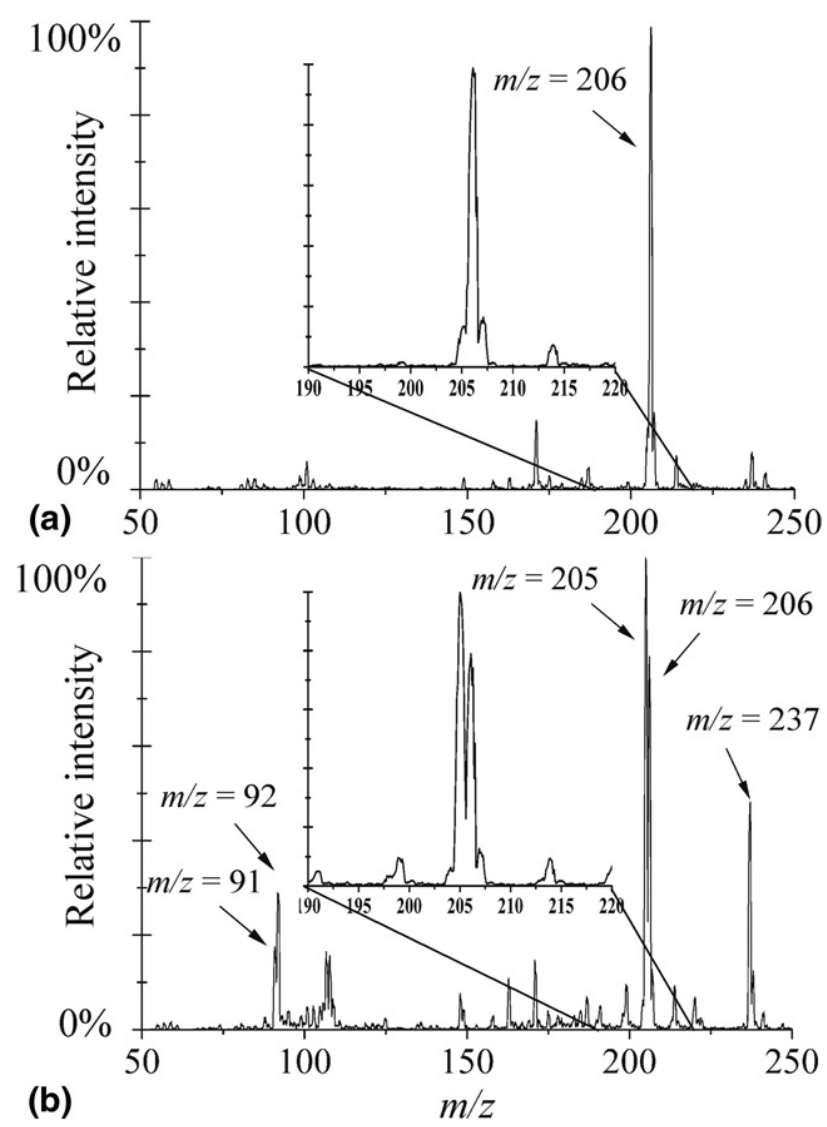

Figure 2. Positive ion APPI mass spectra of 2,6-DtB-4-MPyr, which have a gas-phase concentration of $\sim 2 \mathrm{ppb}$. (a) The analyte is dissolved in hexane and (b) in hexane:toluene (9:1). The main peaks are the $[\mathrm{M}]^{+\cdot}$ ion at $m / z 205,[\mathrm{M}+\mathrm{H}]^{+}$at $m / z 206$, and $[\mathrm{M}+$ $\left.\mathrm{O}_{2}\right]^{+\cdot}$ at $m / z 237$. Toluene produces the ion $[\mathrm{M}-\mathrm{H}]^{+}$at $m / z 91$ and radical cation $[\mathrm{M}]^{+\cdot}$ at $\mathrm{m} / \mathrm{z}$ 92. Declustering potential $=28 \mathrm{~V}$.

cation is seen together with the analyte radical cation suggests that it is needed for effective formation of the $[\mathrm{M}]^{+\cdot}$ ion.

For 2,6-DtBPyr and 2,6-DtB-4-MPyr, oxygen adduct $\left[\mathrm{M}+\mathrm{O}_{2}\right]^{+\cdot}$ ions at $m / z 223$ and 237 , respectively, were observed in some of the APPI mass spectra, which turned out to be useful in explaining the mobility data (see the Mobilities of the Compounds section). For the samples dissolved in hexane:toluene (9:1) this ion was clearly observed (Figure $2 \mathrm{~b}$ ). Previously, $\mathrm{O}_{2}$ adduct ions have been observed to be formed in positive APPI for benzene [49], for a $\beta$-distonic ion $\left(\mathrm{C}_{5} \mathrm{H}_{5} \mathrm{~N}^{+}-\mathrm{CH}_{2} \mathrm{CH}_{2}\right)$ reacting with $\mathrm{O}_{2}$ [50] and for distonic isomers of pyridine radical cation [51]. To confirm the structures of the oxygen adducts, their product ion mass spectra were measured and compared to product ion mass spectra of the radical cations and protonated molecules of 2,6DtBPyr and 2,6-DtB-4-MPyr (Table 1). For both of the oxygen adducts oxygen $\left(\mathrm{O}_{2}\right)$ loss was observed and the other product ions seen in the mass spectrum were similar to the ones observed for the radical cation of the studied molecules. For both the radical cations and the protonated molecule of 2,6-DtBPyr and 2,6-DtB-4-MPyr, fragmentation of the side groups was observed. Product ion 
Table 1. Product ion mass spectra of 2,6-di-tert-butylpyridine and 2,6-di-tert-butyl-4-methylpyridine with and without toluene in the sample solution

\begin{tabular}{|c|c|c|c|c|c|c|c|c|}
\hline \multirow{2}{*}{$\frac{\text { Compound }}{2,6-\mathrm{D} t \text { BPyr in hexane }}$} & \multirow{2}{*}{$\begin{array}{c}\mathrm{PI} \\
192\end{array}$} & \multicolumn{6}{|c|}{ Product ions, proposed cleaved species } & \multirow{2}{*}{ CE } \\
\hline & & $\begin{array}{r}177(70) \\
\left(-\mathrm{CH}_{3}\right)\end{array}$ & $\begin{array}{l}176(100) \\
\left(-\mathrm{CH}_{4}\right)\end{array}$ & $\begin{array}{c}162(70) \\
\left(-\mathrm{C}_{2} \mathrm{H}_{6}\right)\end{array}$ & $\begin{array}{c}149(10) \\
\left(-\mathrm{C}_{3} \mathrm{H}_{7}\right)\end{array}$ & $\begin{array}{l}135(10) \\
\left(-\mathrm{C}_{4} \mathrm{H}_{9}\right)\end{array}$ & & \\
\hline 2,6-DtBPyr in hexane:toluene (9:1) & 191 & $\begin{array}{r}176(40) \\
\left(-\mathrm{CH}_{3}\right)\end{array}$ & $\begin{array}{l}149(100) \\
\left(-\mathrm{C}_{3} \mathrm{H}_{6}\right)\end{array}$ & & & & & 15 \\
\hline & 192 & $\begin{array}{r}177(70) \\
\left(-\mathrm{CH}_{3}\right)\end{array}$ & $\begin{array}{l}176(100) \\
\left(-\mathrm{CH}_{4}\right)\end{array}$ & $\begin{array}{c}162(70) \\
\left(-\mathrm{C}_{2} \mathrm{H}_{6}\right)\end{array}$ & $\begin{array}{c}161(20) \\
\left(-\mathrm{C}_{2} \mathrm{H}_{7}\right)\end{array}$ & $\begin{array}{l}149(20) \\
\left(-\mathrm{C}_{3} \mathrm{H}_{7}\right)\end{array}$ & $\begin{array}{l}135(20) \\
\left(-C_{4} \mathrm{H}_{9}\right)\end{array}$ & 40 \\
\hline & 223 & $\begin{array}{c}191(80) \\
\left(-O_{2}\right)\end{array}$ & $\begin{array}{c}176(30) \\
\left(-\mathrm{O}_{2}-\mathrm{CH}_{3}\right)\end{array}$ & $\begin{array}{c}149(100) \\
\left(-\mathrm{O}_{2}-\mathrm{C}_{3} \mathrm{H}_{6}\right)\end{array}$ & & & & 22 \\
\hline 2,6-DtB-4-MPyr in hexane & 206 & $\begin{array}{c}191(100) \\
\left(-\mathrm{CH}_{3}\right)\end{array}$ & $\begin{array}{l}190(80) \\
\left(-\mathrm{CH}_{4}\right)\end{array}$ & $\begin{array}{c}176(40) \\
\left(-\mathrm{C}_{2} \mathrm{H}_{6}\right)\end{array}$ & $\begin{array}{c}163(10) \\
\left(-\mathrm{C}_{3} \mathrm{H}_{7}\right)\end{array}$ & $\begin{array}{l}149(10) \\
\left(-\mathrm{C}_{4} \mathrm{H}_{9}\right)\end{array}$ & & 38 \\
\hline 2-DtB-4-MPyr in hexane:toluene (9:1) & 205 & $\begin{array}{c}204(10) \\
(-\mathrm{H})\end{array}$ & $\begin{array}{l}190(30) \\
\left(-\mathrm{CH}_{3}\right)\end{array}$ & $\begin{aligned} & 163(100) \\
&\left(-\mathrm{C}_{3} \mathrm{H}_{6}\right)\end{aligned}$ & $\begin{array}{c}149(10) \\
\left(-\mathrm{C}_{4} \mathrm{H}_{8}\right)\end{array}$ & & & 15 \\
\hline & 206 & $\begin{array}{c}191(100) \\
\left(-\mathrm{CH}_{3}\right)\end{array}$ & $\begin{array}{l}190(80) \\
\left(-\mathrm{CH}_{4}\right)\end{array}$ & $\begin{array}{c}176(50) \\
\left(-\mathrm{C}_{2} \mathrm{H}_{6}\right)\end{array}$ & $\begin{array}{c}163(20) \\
\left(-\mathrm{C}_{3} \mathrm{H}_{7}\right)\end{array}$ & $\begin{array}{l}149(10) \\
\left(-\mathrm{C}_{4} \mathrm{H}_{9}\right)\end{array}$ & & 38 \\
\hline & 237 & $\begin{array}{c}205(100) \\
\left(-\mathrm{O}_{2}\right)\end{array}$ & $\begin{array}{c}204(20) \\
\left(-\mathrm{O}_{2}-\mathrm{H}\right)\end{array}$ & $\begin{array}{c}190(30) \\
\left(-\mathrm{O}_{2}-\mathrm{CH}_{3}\right)\end{array}$ & $\begin{array}{c}163(100) \\
\left(-\mathrm{O}_{2}-\mathrm{C}_{3} \mathrm{H}_{6}\right)\end{array}$ & & & 22 \\
\hline
\end{tabular}

Relative abundances of product ions and the species lost are presented in brackets. Product ions with a relative abundance equal to or more than $10 \%$ are presented. All the analytes have a gas phase concentration of 2 to $4 \mathrm{ppb}$.

$\mathrm{PI}=$ precursor ion $(\mathrm{m} / \mathrm{z})$; CE $=$ collision energy $(\mathrm{V})$.

spectra of the ions $\mathrm{m} / \mathrm{z} 191$ and 205 indicated that traces of oxygen adduct ion were sometimes observable in the product ion spectra. This further indicates that for the both radical cation species oxygen adduct formation is favorable.

1- and 2-naphthol behaved similarly in mass spectrometric analysis, and the APPI mass spectra measured for samples dissolved in hexane show both the radical cation $[\mathrm{M}]^{+\cdot}$ at $m / z 144$ and protonated molecule $[\mathrm{M}+$ $\mathrm{H}^{+}$at $\mathrm{m} / \mathrm{z} 145$ with varying relative intensities; typically, the $[\mathrm{M}+\mathrm{H}]^{+}$ion has a clearly higher intensity and the peak $\mathrm{m} / \mathrm{z} 144$ is relatively small. But when the samples are dissolved in hexane:toluene (9:1), the radical cation $[\mathrm{M}]^{+\cdot}$ at $\mathrm{m} / \mathrm{z} 144$ clearly has the higher intensity and a relatively small peak is seen at $\mathrm{m} / \mathrm{z} 145$. This is quite well in line with an earlier study where 2-naphthol in acetonitrile produced only the $[\mathrm{M}]^{+\cdot}$ ion at $m / z 144$ when the dopant was toluene or anisole [52], and when the solvent was hexane and toluene was dopant a small amount of the $[\mathrm{M}+\mathrm{H}]^{+}$ion at $m / z 145$ was produced along with the radical cation [41].

In addition to these two ions, which are most relevant for this study, an interesting ion-molecule reaction product ion with an additional 10 mass units compared with the $[\mathrm{M}+\mathrm{H}]^{+}$ion was observed at $m / z 155$ for both the naphthols. This ion was observed clearly when the $[\mathrm{M}+\mathrm{H}]^{+}$ion had a large intensity with a high declustering potential $(80 \mathrm{~V})$. At these conditions a small peak at $m / z 127$ was also seen in the APPI mass spectra, most likely formed via water loss from the protonated molecule. In the product ion mass spectrum of $\mathrm{m} / \mathrm{z} 155$, fragment ions $\mathrm{m} / \mathrm{z} 127$ and 145 are seen. Interestingly, the ion $\mathrm{m} / \mathrm{z} 155$ was also often observed in the product ion mass spectrum of $m / z 145$, where the ion $\mathrm{m} / \mathrm{z} 127$ is also observed. These findings suggest that the $[\mathrm{M}+\mathrm{H}]^{+}$ion, at $m / z 145$, loses water $\left(\mathrm{M}_{\mathrm{r}}=18\right)$ to form $\mathrm{m} / \mathrm{z} 127$, which reacts further, for example with $\mathrm{CO}\left(\mathrm{M}_{\mathrm{r}}=28\right)$ or other species capable of donating $\mathrm{CO}$, to form ion [M + $\mathrm{H}-\mathrm{H}_{2} \mathrm{O}+\mathrm{CO}^{+}$at $m / z 155$, a reaction which can also happen in reverse in the collision chamber. The origin of reacting neutral species could be trace impurities in the collision gas. The corresponding reaction product, i.e., removal of $\mathrm{CO}$ and addition of water, has recently been reported to occur for isoquinoline-3carboxamides [53].

\section{Mobilities of the Compounds}

The mass-selected mobility data is summarized in Table 2 , where the values are absolute reduced mobilities calculated using Formula 1. The behavior of the compounds is discussed below in more detail. Since 2,6$\mathrm{D} t \mathrm{BPyr}$ is proposed to be used as a mobility standard [39], the repeatability of the mobility measurements for it was looked into in more detail. The relative standard deviation of mass-selected reduced mobility for the $[\mathrm{M}+\mathrm{H}]^{+}$ion of 2,6-DtBPyr in hexane and with a gas-phase concentration of about $2 \mathrm{ppb}$ was $0.7 \%(n=$ $\left.13, \mathrm{~K}_{0}=1.49 \mathrm{~cm}^{2} / \mathrm{Vs}\right)$.

\section{Pyridine}

The mass-selected mobility spectrum of the pyridine [M + $\mathrm{H}^{+}$ion at $\mathrm{m} / z 80$ shows two main peaks, $\mathrm{K}_{0}=2.04$ and $1.69 \mathrm{~cm}^{2} / \mathrm{Vs}$, when hexane is the solvent (Figure 3a). The latter mobility peak is expected to be due to a proton-bound dimer because its intensity increases when the gas-phase concentration of pyridine was doubled; even a dimer mass peak was not observed in a full scan mass spectrum. Symmetric proton-bound dimers are commonly formed under ambient conditions for a wide range of molecules: alcohols, ketones, ethers, acetates, aliphatic amines, and aromatic amines [54-56]. An additional reason for us to expect that the 
Table 2. Summary of the reduced mobilities, $\mathrm{K}_{0}\left(\mathrm{~cm}^{2} / \mathrm{Vs}\right)$, measured with IMS-MS. Samples are dissolved in hexane or hexane:toluene (9:1) and typically the values are based on measurements made using both of the solvents. Typically the mobility values obtained with different solvents were the same within the experimental error. The numbers represent the peak numbers in decreasing mobility order as they appear in the mass-selected mobility spectra

\begin{tabular}{|c|c|c|c|c|}
\hline Molecule & Mass $(u)$ & 1st $\left(\mathrm{K}_{0}\right)$ & 2nd $\left(\mathrm{K}_{0}\right)$ & $3 \mathrm{rd}\left(\mathrm{K}_{0}\right)$ \\
\hline Pyridine $\left([\mathrm{M}+\mathrm{H}]^{+} m / z 80\right)$ & 79 & 2.04 & $1.69^{a}$ & $1.63^{b}$ \\
\hline Pyridine $\left([\mathrm{M}+91]^{+} \mathrm{m} / \mathrm{z} 170\right)^{\mathrm{b}}$ & 79 & 1.64 & & \\
\hline $2-t B P y r\left([\mathrm{M}+\mathrm{H}]^{+} m / z 136\right)$ & 135 & 1.73 & & \\
\hline 2,6-DtBPyr ([M] $\left.{ }^{+\cdot} \mathrm{m} / \mathrm{z} 191\right)^{\mathrm{b}}$ & 191 & 1.45 & & \\
\hline 2,6-DtBPyr $\left([\mathrm{M}+\mathrm{H}]^{+} m / z\right.$ 192) & 191 & 1.50 & $1.45^{\mathrm{b}, \mathrm{c}}$ & \\
\hline 2,6-DtBPyr $\left(\left[\mathrm{M}+\mathrm{O}_{2}\right]^{+\cdot} \mathrm{m} / \mathrm{z} 223\right)^{\mathrm{b}}$ & 191 & 1.45 & & \\
\hline 2,6-DtB-4-MPyr ([M] $\left.]^{+\cdot} m / z 205\right)^{\mathrm{b}}$ & 205 & 1.38 & & \\
\hline 2,6-DtB-4-MPyr ([M + H] $\left.]^{+} m / z 206\right)$ & 205 & 1.42 & $1.38^{\mathrm{b}, \mathrm{c}}$ & \\
\hline 2,6-DtB-4-MPyr $\left(\left[\mathrm{M}+\mathrm{O}_{2}\right]^{+\cdot} \mathrm{m} / z 237\right)^{\mathrm{b}}$ & 205 & 1.39 & & \\
\hline 1-Naphthol $\left([\mathrm{M}]^{+\cdot} \mathrm{m} / \mathrm{z} 144\right)$ & 144 & 1.72 & & \\
\hline 1-Naphthol $\left([\mathrm{M}+\mathrm{H}]^{+} \mathrm{m} / z\right.$ 145) & 144 & 1.68 & $1.50^{d}$ & $1.32^{d}$ \\
\hline 1-Naphthol $\left(\left[\mathrm{M}+\mathrm{H}-\mathrm{H}_{2} \mathrm{O}+\mathrm{CO}\right]^{+} \mathrm{m} / z\right.$ 155) & 144 & 1.68 & & \\
\hline 2-Naphthol ([M] $\left.{ }^{+\cdot} \mathrm{m} / \mathrm{z} 144\right)$ & 144 & 1.73 & & \\
\hline 2-Naphthol $\left([\mathrm{M}+\mathrm{H}]^{+} \mathrm{m} / z\right.$ 145) & 144 & 1.67 & $1.50^{\mathrm{d}}$ & $1.32^{d}$ \\
\hline 2-Naphthol $\left(\left[\mathrm{M}+\mathrm{H}-\mathrm{H}_{2} \mathrm{O}+\mathrm{CO}\right]^{+} m / z\right.$ 155) & 144 & 1.67 & & \\
\hline
\end{tabular}

a Dimer.

bPeaks observed only clearly in hexane:toluene (9:1).

cMost likely ${ }^{13} \mathrm{C}$ isotope peak of the ion $\mathrm{m} / \mathrm{z} 191$ or 205.

dMinor peaks that are observed sporadically.

second peak is a dimer peak is the observation that during one measurement day it was observed that the first peak changed relatively much, about 0.06 units, to lower mobility, but the second peak still had a mobility of $1.69 \mathrm{~cm}^{2} / \mathrm{Vs}$. We believe that the change could be due to sample solvent somehow "overloading" the drift tube on this one day, since the next day's measurement of the mobility of the first peak was as expected. It has been reported that mobility of monomers can be more dependent on measuring conditions than dimers [57]. Interestingly, when hexane:toluene (9:1) is used, a new peak with a lower mobility, $\mathrm{K}_{0}=1.63 \mathrm{~cm}^{2} / \mathrm{Vs}$, appears while measuring mass-selected mobility of the ion $\mathrm{m} / \mathrm{z}$ 80 (Figure $3 b$ ). This mobility peak is most likely due to some kind of pyridine adduct ion. It was also observed that an adduct ion $\mathrm{m} / \mathrm{z} 170$ produced a mobility peak with this same mobility, i.e., $\mathrm{K}_{0}=1.63 \mathrm{~cm}^{2} / \mathrm{Vs}$. An ion $\mathrm{m} / \mathrm{z} 170$ was typically seen with low intensity in APPI mass spectra of pyridine measured from hexane:toluene (9:1) solution. Its product ion mass spectrum indicated the presence of a fragment ion $m / z$ 91, which could mean that the ion $m / z 170$ is a benzyl cation adduct of pyridine $[\mathrm{M}+91]^{+}$. The presence of some other product ions was also indicated (e.g., $m / z 78$ and 80 ) but unfortunately the quality of the product ion spectrum was not very good. Identification of the structure of the ion $\mathrm{m} / \mathrm{z} 170$ is not possible without further measurements.

\section{2-tert-Butylpyridine, 2,6-di-tert-Butylpyridine and 2,6-di-tert-butyl-4-Methylpyridine}

The mass-selected mobility spectra of 2-tBPyr measured for its $[\mathrm{M}+\mathrm{H}]^{+}$ion produced one peak with a mobility of $\mathrm{K}_{0}=1.73 \mathrm{~cm}^{2} / \mathrm{Vs}$ (Table 2) when the solvent was hexane or hexane:toluene (9:1). For 2,6-DtBPyr (Figure
$4 \mathrm{a}$ and b) and 2,6-DtB-4-MPyr one clear mobility peak was observed in the mass-selected mobility spectra of the $[\mathrm{M}+\mathrm{H}]^{+}$ion, with $\mathrm{K}_{0}=1.50$ and $1.42 \mathrm{~cm}^{2} / \mathrm{Vs}$, respectively, whereas for the $[\mathrm{M}]^{+\cdot}$ ions mobility peaks were observed at $\mathrm{K}_{0}=1.45$ and $1.38 \mathrm{~cm}^{2} / \mathrm{Vs}$, respectively. Small mobility peaks were also observed at $\mathrm{K}_{0}=$ 1.45 and $1.38 \mathrm{~cm}^{2} / \mathrm{Vs}$ for the $[\mathrm{M}+\mathrm{H}]^{+}$ion of $2,6-$ DtBPyr and 2,6-DtB-4-MPyr, respectively, but it is expected that these are isotope peaks of ions $m / z 191$ and 205, respectively. Mass-selected mobility spectra of the $\left[\mathrm{M}+\mathrm{O}_{2}\right]^{+\cdot}$ ions of these two compounds produced mobility peaks with corresponding mobilities as measured for their $[\mathrm{M}]^{+\cdot}$ ions (Table 2). Some mobility measurements were also done for 2,6-DtBPyr using the IMS-FP instrument and APPI. Two mobility peaks were observed when the sample solvent was either hexane: toluene (Figure 5) or pentane:toluene, with mobilities of $\mathrm{K}_{0}=1.47$ and $1.42 \mathrm{~cm}^{2} / \mathrm{Vs}$ and $\mathrm{K}_{0}=1.46$ and 1.42 $\mathrm{cm}^{2} / \mathrm{Vs}$, respectively. A reaction ion peak was also observed. However, when the sample solvent was methanol:toluene (9:1) only one mobility peak, at $\mathrm{K}_{0}=$ $1.46 \mathrm{~cm}^{2} / \mathrm{Vs}$, was seen. The small difference in reduced mobility between these two instruments was examined previously and it could be corrected by adjusting the mobility scale [58].

Interestingly, for both 2,6-DtBPyr and 2,6-DtB-4MPyr the radical cation has a lower mobility than the protonated molecule. It is most likely that 2,6-DtBPyr and 2,6-DtB-4-MPyr form oxygen adducts $\left[\mathrm{M}+\mathrm{O}_{2}\right]^{+}$, causing slower drift time due to the increased mass. However, we could not entirely rule out the possibility that radical cations interact strongly with the residual oxygen in the drift gas and therefore drift slower. Borsdorf et al. have previously reported that protonated anilines have lower reduced mobilities than radical 


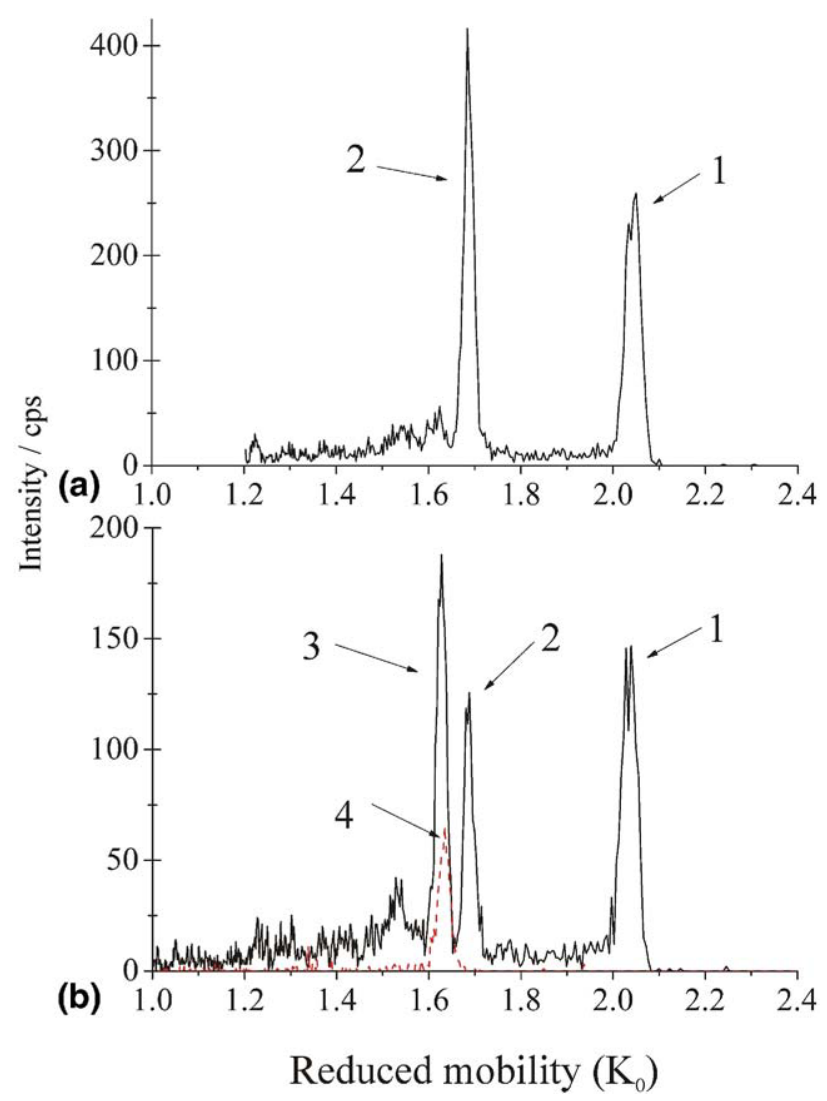

Figure 3. Positive ion APPI mass-selected ion mobility spectra of pyridine. (a) $[\mathrm{M}+\mathrm{H}]^{+}$ion at $\mathrm{m} / \mathrm{z} 80$ (solid line); the gas-phase concentration is $\sim 10 \mathrm{ppb}$ and the sample is dissolved in hexane. (b) $[\mathrm{M}+\mathrm{H}]^{+}$ion at $\mathrm{m} / \mathrm{z} 80$ (solid line) and $[\mathrm{M}+91]^{+}$ion at $\mathrm{m} / \mathrm{z}$ 170 (dotted line); the gas-phase concentration is $\sim 5 \mathrm{ppb}$ and the sample is dissolved in hexane:toluene (9:1). Peaks are: (1) monomer ion with $\mathrm{K}_{0}=2.04 \mathrm{~cm}^{2} / \mathrm{Vs}$, (2) dimer ion with $\mathrm{K}_{0}=1.69$ $\mathrm{cm}^{2} / \mathrm{Vs}$, (3) and (4) adduct ion with mobilities of $\mathrm{K}_{0}=1.63$ and $1.64 \mathrm{~cm}^{2} /$ Vs for ions at $\mathrm{m} / \mathrm{z} 80$ and 170 , respectively.

cations [38], which is the opposite of our case. The explanation given was that in the experimental conditions used, protonated anilines interact significantly more with water in the drift tube than the radical cations. Due to this, protonated anilines are heavier and drift slower than radical cations. The solvation and clustering of protonated amines and pyridines has been studied by Meot-Ner et al. with NBS pulsed highpressure mass spectrometer [59], the results of which suggest that steric effects cause unfavorable entropy effects for hydration of protonated 2,6-DtBPyr [59]. Based on this, we are expecting that protonated 2,6DtBPyr and 2,6-DtB-4-MPyr do not interact strongly with water in the drift tube. Formation of an oxygen adduct $\left[\mathrm{M}+\mathrm{O}_{2}\right]^{+\cdot}$ was not observed for pyridine and 2-tBPyr. This could mean that both of the tert-butyl groups are needed to "lock" the oxygen atom together with ionized 2,6-DtBPyr and 2,6-DtB-4-MPyr to form a stable adduct. Also, it is clear based on the data that radical cations are needed for oxygen adduct formation, and the data show that formation of radical cations for pyridine and 2-tBPyr is not very favorable in the conditions used. We could not find ionization energies (IE) for the tert-butyl substituted pyridines, but we are expecting that formation of a radical cation via chargetransfer from a toluene radical cation is favorable only for 2,6-DtBPyr and 2,6-DtB-4-MPyr, so that the IE of toluene $(\mathrm{IE}=8.828 \mathrm{eV})$ is higher than that of these two pyridines. This estimation is based on literature values for pyridine, 2-methylpyridine, and 2,6-dimethylpyridine, which have ionization energies of IE $=9.26 \mathrm{eV}, 9.2 \mathrm{eV}$ (range given is 9.02-9.4) and $8.86 \mathrm{eV}$, respectively [60].

Note that 2,6-DtBPyr is used as a mobility standard [61] by some research groups [39, 58, 62]. It can be used for calibration if one makes sure, by selecting appropriate ionization conditions, that the mobility of the protonated molecule is measured.

\section{1- and 2-Naphthol}

These two isomeric compounds produced within experimental error the same mobility values for their radical cations and protonated molecules (Table 2). Massselected mobilities of the radical cation and protonated molecule of 1-naphthol measured for a sample in hex-

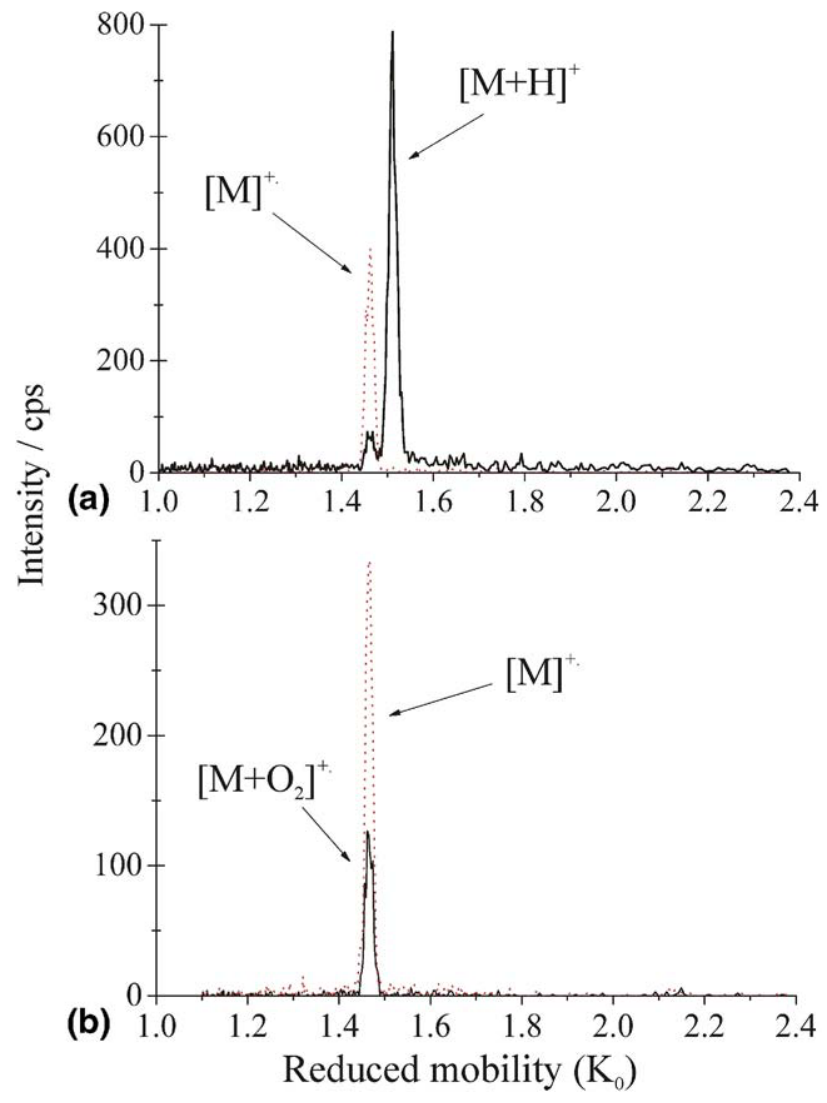

Figure 4. Positive ion APPI mass-selected mobility spectra of 2,6-DtBPyr. The gas-phase concentration is $\sim 2 \mathrm{ppb}$ and the sample is dissolved in hexane:toluene (9:1). (a) Ion [M] ${ }^{+\cdot}$ at $m / z 191$ (dotted line) has a $\mathrm{K}_{0}=1.45 \mathrm{~cm}^{2} / \mathrm{Vs}$ and ion $[\mathrm{M}+\mathrm{H}]^{+}$at $m / z 192$ (solid line) has a $\mathrm{K}_{0}=1.49 \mathrm{~cm}^{2} /$ Vs. (b) Both ions [M] ${ }^{+\cdot}$ at $\mathrm{m} / z 191$ (dotted line) and $\left[\mathrm{M}+\mathrm{O}_{2}\right]^{+\cdot}$ at $\mathrm{m} / \mathrm{z} 223$ (solid line) have the same mobility, $\mathrm{K}_{0}=1.45 \mathrm{~cm}^{2} / \mathrm{Vs}$. 


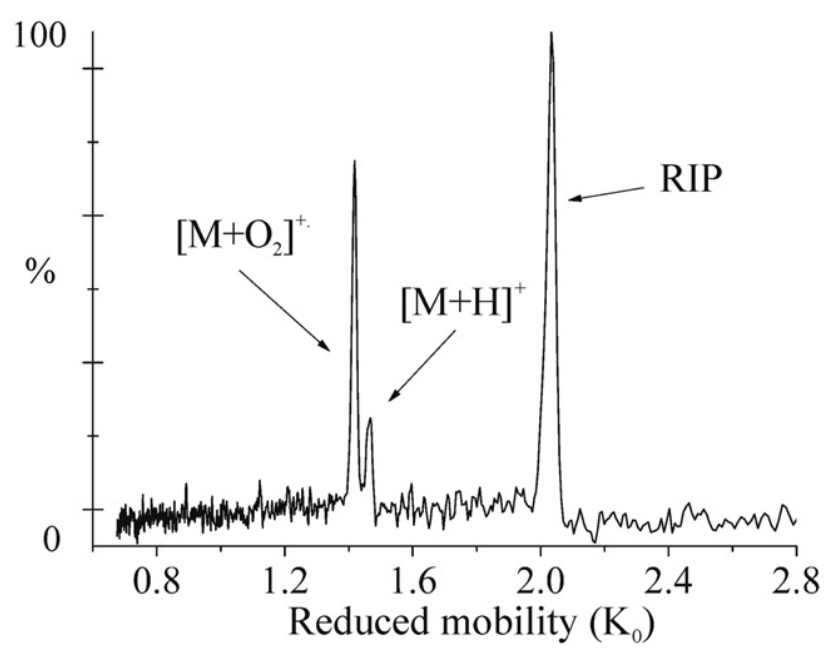

Figure 5. Positive ion APPI ion mobility spectrum of 2,6-D tBPyr measured with IMS-Faraday plate detector. The gas-phase concentration is $\sim 20 \mathrm{ppb}$ and the sample is dissolved in hexane: toluene (9:1). The reduced mobilities of peaks $[\mathrm{M}+\mathrm{H}]^{+}$and $[\mathrm{M}+$ $\left.\mathrm{O}_{2}\right]^{+\cdot}$ are 1.47 and $1.42 \mathrm{~cm}^{2} / \mathrm{Vs}$, respectively. Analyte peak identification is based on IMS-MS data. RIP = reaction ion peak.

ane were $\mathrm{K}_{0}=1.72 \mathrm{~cm}^{2} / \mathrm{Vs}$ and $\mathrm{K}_{0}=1.68 \mathrm{~cm}^{2} / \mathrm{Vs}$, respectively, whereas the corresponding values for 2-naphthol were $\mathrm{K}_{0}=1.73 \mathrm{~cm}^{2} / \mathrm{Vs}$ and $\mathrm{K}_{0}=1.67$ $\mathrm{cm}^{2} / \mathrm{Vs}$. The mobilities of the radical cations for both compounds measured in hexane:toluene (9:1) were the same as in hexane, within experimental error. In these conditions the mass selected mobility measurement of the ion $\mathrm{m} / \mathrm{z} 145$ produced a small peak with the same mobility as measured for the ion $\mathrm{m} / \mathrm{z} 144$, most likely due to isotope effects. Minor peaks with lower mobilities are also sometimes observed for both compounds. Mobility of the ion molecule reaction product $[\mathrm{M}+\mathrm{H}-$ $\left.\mathrm{H}_{2} \mathrm{O}+\mathrm{CO}\right]^{+}$ion at $m / z 155$ has the same mobility for both compounds than their protonated molecules. Interestingly, the radical cation $[\mathrm{M}]^{+\cdot}$ has a higher mobility than the protonated ion $[\mathrm{M}+\mathrm{H}]^{+}$, which is the opposite of what is observed for 2,6-DtBPyr and 2,6DtB-4-MPyr. For 2,6-DtBPyr and 2,6-DtB-4-MPyr, the slower mobility of the radical cation was explained by its ability to form an oxygen adduct ion. In the case of 1- and 2-naphthol, no other than $\left[\mathrm{M}+\mathrm{H}-\mathrm{H}_{2} \mathrm{O}+\right.$ $\mathrm{CO}]^{+}$adduct ions were identified from the measured mass spectra. The most likely explanation for the observed mobility order of the $[\mathrm{M}]^{+}$and $[\mathrm{M}+\mathrm{H}]^{+}$ions of 1- and 2-naphthol is the explanation given by Borsdorf et al. for anilines [38], i.e., protonated molecules interact more with the residual water in the drift gas than radical cations.

\section{Conclusions}

This study demonstrates how radical cations and protonated molecules can be produced and separated with APPI-IMS-MS. Under appropriate measurement conditions, 2,6-DtBPyr and 2,6-DtB-4-MPyr efficiently produced both radical cations $[\mathrm{M}]^{+\cdot}$ and protonated $[\mathrm{M}+$
$\mathrm{H}]^{+}$molecules. The radical cation $[\mathrm{M}]^{+\cdot}$ was observed to have a longer drift time. Further mass spectrometry analysis also revealed the formation of the oxygen adduct ion $\left[\mathrm{M}+\mathrm{O}_{2}\right]^{+}$, which has the same mobility as the radical cation $[\mathrm{M}]^{+}$. The formation of the oxygen adduct is likely to be dependent on the presence of two tert-butyl groups. In case of 1- and 2-naphthol, the radical cation $[\mathrm{M}]^{+\cdot}$ has a higher mobility than the protonated $[\mathrm{M}+\mathrm{H}]^{+}$, which is opposite compared with 2,6-D $t$ BPyr and 2,6-D $t \mathrm{~B}-4-\mathrm{MPyr}$. For pyridine and 2-tBPyr, protonated molecules were the main ions observed and their mobilities are reported. Overall, these findings illustrated how high-resolution IMS is used to separate different ion structures of model compounds, and how MS is used to obtain more information about the different peaks observed with IMS.

\section{Acknowledgments}

The authors acknowledge support for this project by the Academy of Finland (project numbers:114132 and 122018). Jyrki Viidanoja is acknowledged for stimulating conversations. The authors also acknowledge Markus Haapala and Jari Yli-Kauhaluoma from the Division of Pharmaceutical Chemistry of the University of Helsinki. Jaroslaw Puton from the Military University of Technology, Warsaw, Poland, Elina Kalenius from the Department of Chemistry, University of Eastern Finland, and Glenn Spangler are thanked for help.

\section{References}

1. Eiceman, G. A.; Karpas, Z. Ion Mobility Spectrometry, 2nd ed.; CRC Press Taylor and Francis: Boca Raton, 2005; p. 350.

2. Mason, E. A. Ion Mobility: Its Role in Plasma Chromatography. In Plasma Chromatograph, Carr T. W., Eds.; Plenum: New York, 1984; p. 259.

3. Creaser, C. S.; Griffiths, J. R.; Bramwell, C. J.; Noreen, S.; Hill, C. A.; Thomas, C. L. P. Ion Mobility Spectrometry: A Review. Part 1. Structural Analysis by Mobility Measurement. Analyst 2004, 129, 984-994.

4. Kanu, A. B.; Hill, H. H. Jr. Ion Mobility Spectrometry Detection for Gas Chromatography. J. Chromatogr. A 2008, 1177, 12-27.

5. Kanu, A. B.; Dwivedi, P.; Tam, M.; Matz, L.; Hill, H. H. Jr. Ion Mobility-Mass Spectrometry. J. Mass Spectrom. 2008, 43, 1-22.

6. Baumbach, J. Ion Mobility Spectrometry in Scientific Literature and in the International Journal for Ion Mobility Spectrometry (1998-2007). Int. J. Ion Mobility Spectrom. 2008, 11, 3-11.

7. Borsdorf, H.; Eiceman, G. A. Ion Mobility Spectrometry: Principles and Applications. Appl. Spectrosc. Rev. 2006, 41, 323-375.

8. Baumbach, J. Process Analysis Uusing Ion Mobility Spectrometry. Anal. Bioanal. Chem. 2006, 384, 1059-1070.

9. Spangler, G. E. Expanded Theory for the Resolving Power of a Linear Ion Mobility Spectrometer. Int. J. Mass Spectrom. 2002, 220, 399-418.

10. Tarver, E. External Second Gate, Fourier Transform Ion Mobility Spectrometry: Parametric Optimization for Detection of Weapons of Mass Destruction. Sensors 2004, 4, 1-13.

11. Asbury, R. G.; Klasmeier, J.; Hill, H. H. Jr. Analysis of Explosives Using Electrospray Ionization/Ion Mobility Spectrometry (ESI/IMS). Talanta 2000, 50, 1291-1298.

12. Kanu, A. B.; Hill, H. H. Jr. Identity Confirmation of Drugs and Explosives in Ion Mobility Spectrometry using a Secondary Drift Gas. Talanta 2007, 73, 692-699.

13. Baim, M. A.; Eatherton, R. L.; Hill, H. H. Jr. Ion Mobility Detector for Gas Chromatography with a Direct Photoionization Source. Anal. Chem. 1983, 55, 1761-1766.

14. Sysoev, A.; Adamov, A.; Viidanoja, J.; Ketola, R. A.; Kostiainen, R.; Kotiaho, T. Development of an Ion Mobility Spectrometer for use in an Atmospheric Pressure Ionization Ion Mobility spectrometer/mass Spectrometer Instrument for Fast Screening Analysis. Rapid Commun. Mass Spectrom. 2004, 18, 3131-3139.

15. Guevremont, R.; Thekkadath, G.; Hilton, C. K. Compensation Voltage (CV) Peak Shapes Using a Domed FAIMS with the Inner Electrode Translated to Various Longitudinal Positions. J. Am. Soc. Mass Spectrom. 2005, 16, 948-956.

16. Sultan, J.; Gabryelski, W. Structural Identification of Highly Polar Nontarget Contaminants in Drinking Water by ESI-FAIMS-Q-TOF-MS Anal. Chem. 2006, 78, 2905-2917. 
17. Xia, Y.; Wu, S. T.; Jemal, M. LC-FAIMS-MS/MS for Quantification of a Peptide in Plasma and Evaluation of FAIMS Global Selectivity from Plasma Components. Anal. Chem. 2008, 80, 7137-7143.

18. Adamov, A.; Viidanoja, J.; Kärpänoja, E.; Paakkanen, H.; Ketola, R. A.; Kostiainen, R.; Sysoev, A.; Kotiaho, T. Interfacing an Aspiration Ion Mobility Spectrometer to a Triple Quadrupole Mass Spectrometer. Rev. Sci. Instrum. 2007, 78, 044101-044105.

19. Henderson, S. C.; Valentine, S. J.; Counterman, A. E.; Clemmer, D. E. ESI/Ion Trap/Ion Mobility/Time-of-Flight Mass Spectrometry for Rapid and Sensitive Analysis of Biomolecular Mixtures. Anal. Chem. 1999, 71, 291-301.

20. Valentine, S. J.; Counterman, A. E.; Clemmer, D. E. A Database of 660 Peptide Ion Cross Sections: Use of Intrinsic Size Parameters for Bona Fide Predictions of Cross Sections. J. Am. Soc. Mass Spectrom. 1999, 10, $1188-1211$.

21. Kaur-Atwal, G.; Weston, D. J.; Green, P. S.; Crosland, S.; Bonner, P. L. R.; Creaser, C. S. Analysis of Tryptic Peptides using Desorption Electrospray Ionization Combined with Ion Mobility spectrometry/mass Spectrometry. Rapid Commun. Mass Spectrom. 2007, 21, 1131-1138.

22. Merenbloom, S. I.; Koeniger, S. L.; Valentine, S. J.; Plasencia, M. D.; Clemmer, D. E. IMS-IMS and IMS-IMS-IMS/MS for Separating Peptide and Protein Fragment Ions. Anal. Chem. 2006, 78, 2802-2809.

23. Dwivedi, P.; Bendiak, B.; Clowers, B. H.; Hill, H. H. Jr. Rapid Resolution of Carbohydrate Isomers by Electrospray Ionization Ambient Pressure Ion Mobility Spectrometry-Time-of-Flight Mass Spectrometry (ESIAPIMS-TOFMS). J. Am. Soc. Mass Spectrom. 2007, 18, 1163-1175.

24. Dwivedi, P.; Wu, C.; Matz, L. M.; Clowers, B. H.; Siems, W. F.; Hill, H. H. Jr. Gas-Phase Chiral Separations by Ion Mobility Spectrometry. Anal. Chem. 2006, 78, 8200-8206.

25. Karas, M. Separation of Components of an Analysis Sample in an Ion Mobility Spectrometer Using a Supply of Selectively Interactive Gaseous Particles. U.S. Patent 2004, 0178340 A1.

26. Shumate, C. B.; Hill, H. H. Coronaspray Nebulization and Ionization of Liquid Samples for Ion Mobility Spectrometry. Anal. Chem. 1989, 61, 601-606.

27. Clowers, B. H.; Hill, H. H. Jr. Influence of Cation Adduction on the Separation Characteristics of Flavonoid Diglycoside Isomers Using Dual Gate-Ion Mobility-Quadrupole Ion Trap Mass Spectrometry. J. Mass Spectrom. 2006, 41, 339-351.

28. Ruotolo, B. T.; Giles, K.; Campuzano, I.; Sandercock, A. M.; Bateman, R. H.; Robinson, C. V. Evidence for Macromolecular Protein Rings in the Absence of Bulk Water. Science 2005, 310, 1658-1661.

29. Borsdorf, H.; Schelhorn, H.; Flachowsky, J.; Döring, H.; Stach, J. Corona Discharge Ion Mobility Spectrometry of Aliphatic and Aromatic Hydrocarbons. Anal. Chim. Acta 2000, 403, 235-242.

30. Robb, D. B.; Blades, M. W. State-of-the-Art in Atmospheric Pressure Photoionization for LC/MS. Anal. Chim. Acta 2008, 627, 34-49.

31. Raffaelli, A.; Saba, A. Atmospheric Pressure Photoionization Mass Spectrometry. Mass Spectrom. Rev. 2003, 22, 318-331.

32. Cai, S.-S.; Syage, J. A. Comparison of Atmospheric Pressure Photoionization, Atmospheric Pressure Chemical Ionization, and Electrospray Ionization Mass Spectrometry for Analysis of Lipids. Anal. Chem. 2006, $78,1191-1199$

33. Sielemann, S.; Baumbach, J. I.; Schmidt, H.; Pilzecker, P. Detection of Alcohols Using UV-Ion Mobility Spectrometers. Anal. Chim. Acta 2001, 431, 293-301.

34. Baumbach, J. I.; Sielemann, S.; Xie, Z.; Schmidt, H. Detection of the Gasoline Components Methyltert-Butyl Ether, Benzene, Toluene, and $\mathrm{m}$-Xylene using Ion Mobility Spectrometers with a Radioactive and UV Ionization Source. Anal. Chem. 2003, 75, 1483-1490.

35. Borsdorf, H.; Rudolph, M. Gas-Phase Ion Mobility Studies of Constitutional Isomeric Hydrocarbons using Different Ionization Techniques. Int. J. Mass Spectrom. 2001, 208, 67-72.

36. Borsdorf, H.; Nazarov, E. G.; Eiceman, G. A. Atmospheric Pressure Ionization and Gas Phase Ion Mobility Studies of Isomeric Dihalogenated Benzenes using Different Ionization Techniques. Int. J. Mass Spectrom. 2004, 232, 117-126.

37. Borsdorf, H.; Stone, J. A.; Eiceman, G. A. Gas Phase Studies on Terpenes by Ion Mobility Spectrometry using Different Atmospheric Pressure Chemical Ionization Techniques. Int. J. Mass Spectrom. 2005, 246, 19-28.

38. Borsdorf, H.; Neitsch, K.; Eiceman, G. A.; Stone, J. A. A Comparison of the Ion Chemistry for Mono-Substituted Toluenes and Anilines by Three Methods of Atmospheric Pressure Ionization with Ion Mobility Spectrometry. Talanta 2009, 78, 1464-1475.

39. Eiceman, G. A.; Nazarov, E. G.; Stone, J. A. Chemical Standards in Ion Mobility Spectrometry. Anal. Chim. Acta 2003, 493, 185-194.

40. Laakia, J.; Adamov, A.; Jussila, M.; Pedersen, C. S.; Sysoev, A.; Kotiaho, T. Observation of Different Ion Structures in Ion Mobility Spectrometer with Photoionization (APPI). Proceedings of the 17th Annual Conference on Ion Mobility Spectrometry; (ISIMS 2008). Ottawa, Canada, July, 2008.

41. Kauppila, T. J.; Kuuranne, T.; Meurer, E. C.; Eberlin, M. N.; Kotiaho, T.; Kostiainen, R. Atmospheric Pressure Photoionization Mass Spectrometry. Ionization Mechanism and the Effect of Solvent on the Ionization of Naphthalenes. Anal. Chem. 2002, 74, 5470-5479.

42. Syage, J. A. Mechanism of $[\mathrm{M}+\mathrm{H}]^{+}$Formation in Photoionization Mass Spectrometry. J. Am. Soc. Mass Spectrom. 2004, 15, 1521-1533.

43. Robb, D. B.; Blades, M. W. Atmospheric Pressure Photoionization for Ionization of both Polar and Nonpolar Compounds in Reversed-Phase LC/MS. Anal. Chem. 2006, 78, 8162-8164.

44. Adamov, A.; Mauriala, T.; Teplov, V.; Laakia, J.; Pedersen, C. S.; Kotiaho, T.; Sysoev, A. Characterization of a High Resolution Drift Tube Ion Mobility Spectrometer with a Multi-Ion Source Platform. Int. J. Mass Spectrom. (Accepted). (doi:10.1016/j.ijms.2010.02.008)

45. Bradbury, N. E.; Nielsen, R. A. Absolute Values of the Electron Mobility in Hydrogen. Phys. Rev. 1936, 49, 388-393.

46. Tang, X.; Bruce, J. E.; Hill, H. H. Jr. Design and Performance of an Atmospheric Pressure Ion Mobility Fourier Transform Ion Cyclotron Resonance Mass Spectrometer. Rapid Commun. Mass Spectrom. 2007, 21, 1115-1122.

47. Viidanoja, J.; Sysoev, A.; Adamov, A.; Kotiaho, T. TetraAlkylammonium Halides as Chemical Standards for Positive Electrospray Ionization with Ion Mobility spectrometry/mass Spectrometry. Rapid Commun. Mass Spectrom. 2005, 19, 3051-3055.

48. Laakia, J.; Pedersen, C. S.; Adamov, A.; Viidanoja, J.; Sysoev, A.; Kotiaho, T. Sterically Hindered Phenols in Negative Ion Mobility Spectrometry-Mass Spectrometry. Rapid Commun. Mass Spectrom. 2009, 23, 3069-3076.

49. Tubaro, M.; Marotta, M.; Seraglia, R.; Traldi, P. Atmospheric Pressure Photoionization Mechanisms. 2. The Case of Benzene and Toluene. Rapid Commun. Mass Spectrom. 2003, 17, 2423-2429.

50. Yu, S. J.; Holliman, C. L.; Rempel, D. L.; Gross, M. L. The $\beta$-Distonic Ion from the Reaction of Pyridine Radical Cation and Ethene: A Demonstration of High-Pressure Trapping in Fourier Transform Mass Spectrometry. J. Am. Chem. Soc. 1993, 115, 9676-9682.

51. Jobst, K. J.; De Winter, J.; Flammang, R.; Terlouw, J. K.; Gerbaux, P. Differentiation of the Pyridine Radical Cation from its Distonic Isomers by Ion-Molecule Reactions with Dioxygen. Int. J. Mass Spectrom. 2009, $286,83-88$.

52. Kauppila, T.; Kostiainen, R.; Bruins, A. P. Anisole, a New Dopant for Atmospheric Pressure Photoionization Mass Spectrometry of Low Proton Affinity, Low Ionization Energy Compounds. Rapid Commun. Mass Spectrom. 2004, 18, 808-815.

53. Beuck, S.; Schwabe, T.; Grimme, S.; Schlörer, N.; Kamber, M.; Schänzer W.; Thevis, M. Unusual Mass Spectrometric Dissociation Pathway of Protonated Isoquinoline-3-Carboxamides due to Multiple Reversible Water Adduct Formation in the Gas Phase. J. Am. Soc. Mass Spectrom. 2009, 20, 2034-2048.

54. Ewing, R. G.; Eiceman, G. A.; Stone, J. A. Proton-Bound Cluster Ions in Ion Mobility Spectrometry. Int. J. Mass Spectrom. Ion Process 1999, 193, 57-68.

55. Pedersen, C. S.; Lauritsen, F. R.; Sysoev, A.; Viitanen, A. K.; Mäkelä, J. M.; Adamov, A.; Laakia, J.; Mauriala, T.; Kotiaho, T. Characterization of Proton-Bound Acetate Dimers in Ion Mobility Spectrometry. J. Am. Soc. Mass Spectrom. 2008, 19, 1361-1366.

56. Karpas, Z. Ion Mobility Spectrometry of Aliphatic and Aromatic Amines. Anal. Chem. 1989, 61, 684-689.

57. Puton, J. IMS in Quantitative Measurements, IMS Workshop 11.05.2009 in Mikkeli, Finland.

58. Viitanen, A. K.; Mauriala, T.; Mattila, T.; Adamov, A.; Pedersen, C. S.; Mäkelä, J. M.; Marjamäki, M.; Sysoev, A.; Keskinen, J.; Kotiaho, T. Adjusting Mobility Scales of Ion Mobility Spectrometers using 2,6-DtBP as a Reference Compound. Talanta 2008, 76, 1218-1223.

59. Meot-Ner, M.; Sieck, L. W. The Ionic Hydrogen Bond. 1. Sterically Hindered Bonds. Solvation and Clustering of Protonated Amines and Pyridines. J. Am. Chem. Soc. 1983, 105, 2956-2961.

60. NIST Chemistry WebBook. NIST Standard Reference Database Number 69 (Http://webbook.Nist.gov/chemistry/). 2008

61. Kaur-Atwal, G.; O'Connor, G.; Aksenov, A.; Bocos-Bintintan, V.; Pau Thomas, C.; Creaser, C. Chemical Standards for Ion Mobility Spectrometry: A Review. Int. J. Ion Mobility Spectrom. 2009, 12, 1-14.

62. Tadjimukhamedov, F.; Stone, J.; Papanastasiou, D.; Rodriguez, J.; Mueller, W.; Sukumar, H.; Eiceman, G. Liquid Chromatography/Electrospray Ionization/Ion Mobility Spectrometry of Chlorophenols with Full Flow from Large Bore LC Columns. Int. J. Ion Mobility Spectrom. 2008, 11, 51-60. 